\title{
Acceptance of Remote Experiments in Secondary Students
}

\author{
https://doi.org/10.3991/ijoe.v14i05.8678 \\ Nikos Dintsios $\left.{ }^{\bowtie}\right)$, Stamatia Artemi \\ Aristotle University of Thessaloniki, Thessaloniki, Greece \\ nikos.dintsios@gmail.com \\ Hariton Polatoglou \\ Laboratory of Didactics of Physics and Educational Technology, Thessaloniki, Greece
}

\begin{abstract}
In this work, we present research results concerning students' acceptance of the implementation of remote experiments in secondary education. We discuss-analyze two discrete ways of conducting remote experiments and we compare the pertinent data on acceptance. Disparities emerge when the same remote experiments are used as demonstration experiments in classroom and by the students from their own place (assigned homework). The latter seems to be more the favorable for the students to participate in remote experimentation.
\end{abstract}

Keywords - remote experiments, demonstration experiments, students' acceptance, access time

\section{$1 \quad$ Introduction}

More and more remote manipulation of devices in general is becoming part of our everyday reality. Scientists have years ago constructed apparatuses that are controlled from distance. This new field grew very fast and it did not take long for remote experiments and labs to appear at a width range of sciences. It is worth mentioning that when searching in Google using the phrases "Remote Labs" and "Remote Experiments" the results show an increasing trend from 1960 to 2018. The same trend appears when we use Google Scholar for the same phrases (Table 1).

Table 1. Results of Google and Scholar Google Search

\begin{tabular}{|c|l|c|c|c|}
\hline & & $\begin{array}{c}\text { Results } \\
\mathbf{1 9 6 0 - 1 9 8 9}\end{array}$ & $\begin{array}{c}\text { Results } \\
\mathbf{1 9 9 0 - 2 0 0 9}\end{array}$ & $\begin{array}{c}\text { Results } \\
\mathbf{2 0 1 0 - 2 0 1 8}\end{array}$ \\
\hline \multirow{2}{*}{ Search Engine } & \multicolumn{1}{|c|}{ Search Phrase } & & & \\
\hline \multirow{2}{*}{ Google } & "Remote Labs" & 2 & 998 & 12200 \\
\cline { 2 - 5 } & "Remote Experiments" & 2 & 423 & 1960 \\
\hline \multirow{2}{*}{ Scholar Google } & "Remote Labs" & 8 & 1050 & 2890 \\
\cline { 2 - 5 } & "Remote Experiments" & 69 & 1350 & 3200 \\
\hline
\end{tabular}


This raise reflects the efforts that scientists made on constructing remote labs and experiments and in general to control devices from distance. The pre-mentioned increase would not be unreasonable to assume that is linked with the evolution of internet and computers.

In our effort to provide a definition of remote experiments we come up to [1]-[4] and we would summarize that remote experiments have two basic characteristics:

- User and experimental set up are located at different places

- Remote experiments use real experimental setup

When introducing a new educational approach, questions such as the effectiveness and the acceptance of a new method have to be carefully examined. Studies have been carried out concerning the acceptance of remote experiments among students as well as the satisfaction of the latter [5]-[12]. All above studies used questionnaire which included several questions on a number of issues. Among other, the researchers tried to trace if remote experiments helped students and if students liked them. At this point we should stress that all above studies conducted at tertiary education except from Lowe, whose work deals with students aged 9-11. Furthermore, three of the studies above, concern circuits and electronic devices, while all others lie in the field of Mechanics. Our aim is on one hand to involve students in ICT, an aspect which to the best of our knowledge is not that spread in Greek Educational Community and on the other hand to detect what impact has the implementation of remote experiments on electrical circuits applied at Greek Secondary Education (ages from 14-16). This will record the views of Greek students on remote experiments, since this is the first time that remote experiments have been implemented in Greek secondary education.

In our work, an anonymous questionnaire was used (either an on line or a printed version) to trace students views on remote experiments. We concentrate on views which have to do whether they found interesting to conduct remote experiments or not, if they believe that distant activities with real equipment could enhance their understanding of science, if they agree to the statement that the distant activity they performed was easy to use.

Additionally, studies which have been conducted to other fields, such as business, are also focused in customers' (users') views [13]-[16]. From those studies, we adopted a widely used question which has to do with students' (customers') willingness to recommend the specific site to a friend of theirs who is involve in Physics.

\section{$2 \quad$ Method}

According to Greek secondary curriculum students should participate in several experimental physics activities. Those activities could be performed with one of the three discrete ways that nowadays are available:

- Hands on experiment

- Simulation experiment

- Remote experiment 
The above ways can be used either as a demonstration experiment or as an activity which will be carried out either individually or by small groups.

Our educational approach uses remote experiments concerning electrical circuits constructed and adjusted to the Greek secondary education. The experimental set up is settled at Aristotle University of Thessaloniki. Students could conduct one or more of the following remote experiments:

- Confirmation of Ohm's Law for a resistor of constant temperature

- Resistors in series

- Resistors in parallel

- Estimating Planck's constant with a red (or blue) LED

- Electrical behavior of a filament lamp

Detailed analysis of the above experiments is not the intension of the current paper. In figure 1, the dynamic web page to perform one of the available experiments is presented and consists of:

- A schematic circuit

- Details about the experiment

- A slider set the applied voltage to the selected bipolar element

- A link to an anonymous questionnaire

- A real time video streaming window

To conduct an experiment a user should:

- Connect to the site (site address not provided for identification reasons)

- Create an account

- Choose an experiment to conduct

- Download the pertinent worksheet

- Carry out the experiment by applying different voltage values to the selected circuit and complete the worksheet

We used the remote experiments described above, in two discrete ways.

- As a demonstration experiment in the classroom

- As an assigned homework for each individual student

\subsection{Remote experiment as demonstration}

Our sample is a sample of convenience and consists of 125 students 14 to 16 years old attending schools in small towns.

As a demonstration experiment the teacher connects to the site to conduct the experiments and students are given a worksheet. Students can either sit alone or form small groups of 2-3 persons. If the computer lab is available, students can observe the whole experiment process on a PC. Otherwise the class can participate through the usage of a video projector.

Since most of the provided remote experiments fall into the compulsory experiments that students of Greek secondary education must perform with one of the avail- 
able ways (hands-on, simulation or remote experiment) the whole procedure takes place within the normal teaching session (1 didactic hour).

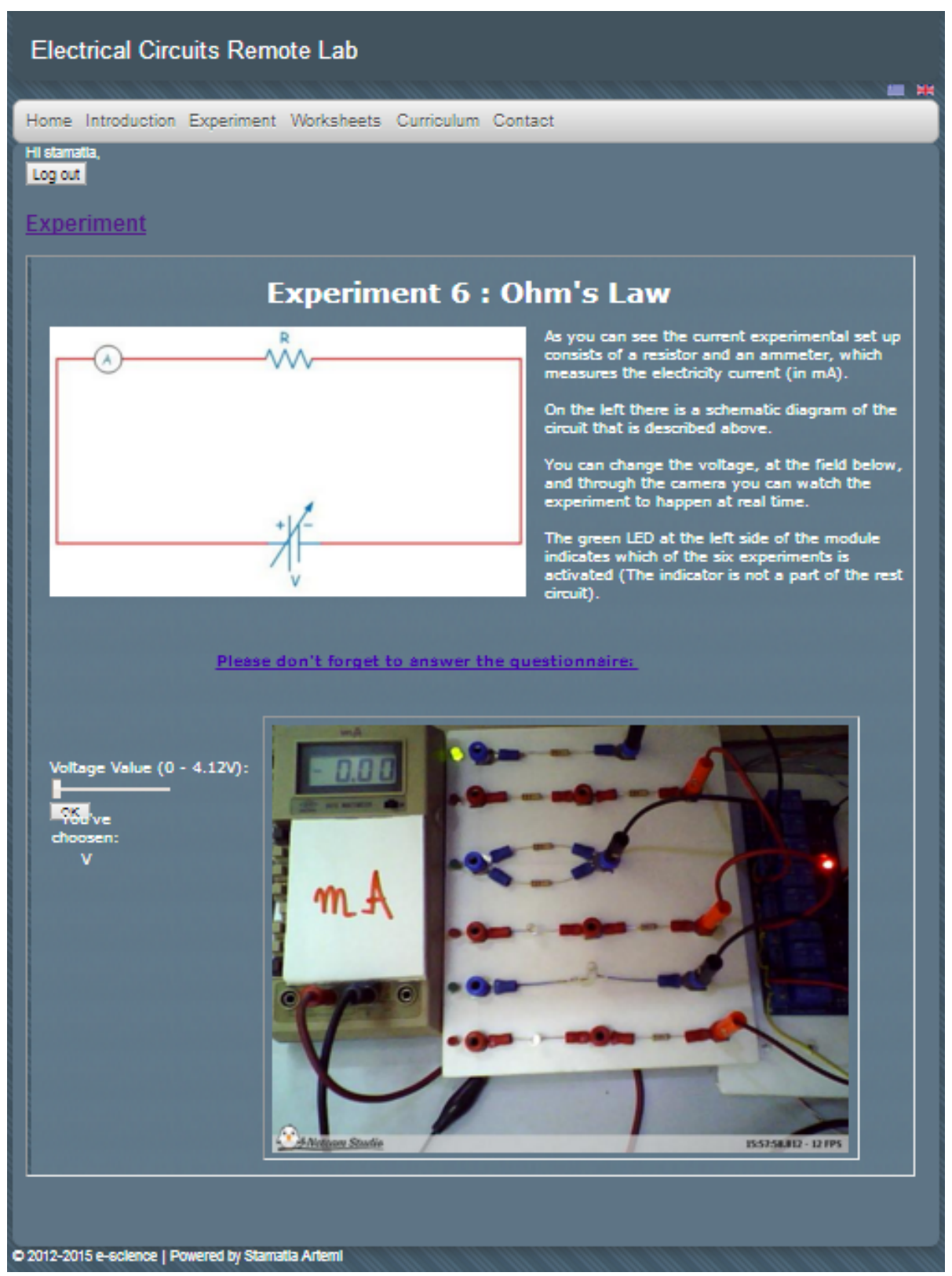

Fig. 1. The specific dynamic web page from which one can carry out a remote experiment on some bipolar electrical and electronic elements. 
The teacher applies several voltage values to the selected circuit, while the students observe and write down the data from the ammeter. The same procedure could be followed, for each available experiment.

The analysis of the recorded data was assigned as homework. Finally, the worksheets were returned to the teacher for assessment and students answered anonymously the questionnaire.

\subsection{Remote experiment as homework}

Another way of conducting a remote experiment is as homework. In this way, we explore many remote experiment features, like, the 24/7 availability, no risk of damaging the equipment, they can be repeated as many times as desired, no need to have multiple instruments, perform the experiments without health risk, can be conducted from home or any other place and from any device. One restriction is though that in most of the cases, including the present one, only one user can perform an experiment at a time. To avoid users' inconvenience when they do not find the experiment available, a scheduling system can be implemented as described by Lowe [17].

Since our site does not support a scheduling system, the teacher should allocate adequate time for each student to have access to the remote experiment, while providing them with all necessary instructions on how to conduct the assigned distant activity. All students are obliged to return the completed worksheet as homework. During this period (from the assignment to handing in the worksheets) students can interact with the teacher and with each other to resolve possible problems, such as account creation, setting voltage values etc.

Our sample this time consists of about 145 students at the same age spectrum with Group A but it is distributed all over Greece. More specifically, there are students who are resident in islands, at small towns in Northern and Southern Greece.

\section{Acceptance of remote experiments}

Both groups of students that performed the remote experiments, where asked the same questions (in statement form). The list of statements that students were asked to respond is listed below.

- Q1: The experimental activity I performed from distance was interesting.

- Q2: Performing real experiments from distance could enhance Physics lessons.

- Q3: The distant activity I carried out helped me understand the lesson.

- Q4: The remote experiment I conducted was easy to use.

- Q5: I would recommend this site to a friend of mine who is involved in Physics.

- Q6: I conducted another remote experiment on my own initiative.

Q6 has been previously posed by Lowe et al., 2013 [7].

To analyze the results in effectively, we used a five-level Likert scale except the last statement which had a Yes and No answer. The results are presented and analyzed in the following paragraphs. 


\subsection{Results for Group A}

Students' (of Group A) involvement in the distant activity, which was to study Ohm's law for a resistor at constant temperature, is:

- Observation of the applied voltage values

- Observation of the current intensity (ammeter)

- Suggestions of the voltage values to be applied (in some cases)

- Predictions of the current through the circuit (in some cases)

- Writing down data (Voltage - Current) on the worksheet

- Completion of the worksheet (as homework)

After returning the competed worksheets, the teacher asks students to answer an anonymous questionnaire either in online or in printed version to record students' views on remote experiments.

The mean values at 5 out of 6 questions are greater than 3 indicating a rather positive view in those aspects. More specifically, $88 \%$ of students Agreed / Strongly Agreed that remote experiments can enhance Physics lessons which reflect a 4.54 mean value. Another result that we have to point out is the low percentage of students who conducted in addition another remote experiment on their own initiative (13.7\%). Although this percentage is low it shows that the students like to explore the features that are available. This result is especially important for physics which is not in the likings of the Greek students. Results of Group A are presented in Table 2.

Table 2. Summarizing results of Group A

\begin{tabular}{|c|c|c|c|c|c|c|c|c|}
\hline no. & Question & $\begin{array}{c}1 \\
\text { Strongly } \\
\text { Disagree } \\
\text { (\%) }\end{array}$ & $\begin{array}{c}2 \\
\text { Disa- } \\
\text { gree } \\
(\%)\end{array}$ & \begin{tabular}{|c|} 
\\
Neither \\
agree nor \\
disagree \\
$(\%)$ \\
\end{tabular} & $\begin{array}{c}4 \\
\text { Agree } \\
(\%)\end{array}$ & \begin{tabular}{|c|}
5 \\
Strong- \\
ly \\
Agree \\
$(\%)$ \\
\end{tabular} & $\begin{array}{l}\text { Mean } \\
\text { Value }\end{array}$ & $\begin{array}{l}\text { Stand } \\
\text { ard } \\
\text { Devia- } \\
\text { tion }\end{array}$ \\
\hline Q1 & $\begin{array}{l}\text { The experimental activity I per- } \\
\text { formed from distance was inter- } \\
\text { esting. }\end{array}$ & 5.00 & 10.00 & 33.00 & 21.00 & 31.00 & 3.63 & 1.16 \\
\hline Q2 & $\begin{array}{l}\text { Performing real experiments from } \\
\text { distance could enhance Physics } \\
\text { lessons. }\end{array}$ & 2.00 & 4.00 & 6.00 & 15.00 & 73.00 & 4.54 & 0.89 \\
\hline Q3 & $\begin{array}{l}\text { The distant activity I carried out } \\
\text { helped me understand the lesson. }\end{array}$ & 13.00 & 7.00 & 28.00 & 27.00 & 25.00 & 3.44 & 1.29 \\
\hline Q4 & $\begin{array}{l}\text { The remote experiment I conduct- } \\
\text { ed was easy to use. }\end{array}$ & 9.00 & 4.00 & 41.00 & 19.00 & 27.00 & 3.51 & 1.18 \\
\hline Q5 & $\begin{array}{l}\text { I would recommend this site to a } \\
\text { friend of mine who is involved in } \\
\text { Physics. }\end{array}$ & 12.00 & 13.00 & 20.00 & 29.00 & 26.00 & 3.45 & 1.32 \\
\hline & & \multicolumn{4}{|c|}{ No } & \multicolumn{3}{|c|}{ Yes } \\
\hline Q6 & $\begin{array}{l}\text { I conducted another remote } \\
\text { experiment on my own initiative. }\end{array}$ & \multicolumn{4}{|c|}{86.30} & \multicolumn{3}{|c|}{13.70} \\
\hline
\end{tabular}




\subsection{Results for Group B}

In contrast to students of Group A, students of Group B had a more active participation in performing the same remote experiment. After a short introduction in the classroom, they were assigned to conduct a remote experiment from their home, on a device of their choice (PC, tablet, smart phone), and return a completed worksheet a week later. To accomplish the requested task they had to

- Connect to the site (site address not provided for identification reasons) and create an account

- Select the remote experiment

- Choose different voltage values to apply to the circuit

- Collect the pertinent data through the web camera

- Follow instructions to complete the worksheet on their own

From students' responses we can conclude that they are positively inclined since at 5 out of 6 questions the mean value is greater than 3 . More specific, $81 \%$ of Group B students Agree/ Strongly Agree with the statement that remote experiments can enhance physics classes, while $74 \%$ of students would recommend the site to a friend of his/her who is involved in physics class. A very important finding is that 4 out of ten students, $(41 \%)$ conducted another experiment on their own initiative. This represents a threefold increase compared to group A, and speaks loud on the importance of the remote experiments. Results of Group B are presented in Table 3.

Table 3. Summarizing results of Group B

\begin{tabular}{|c|c|c|c|c|c|c|c|c|}
\hline no. & Question & $\begin{array}{c}1 \\
\text { Strongly } \\
\text { Disagree } \\
\text { (\%) }\end{array}$ & $\begin{array}{c}2 \\
\text { Disa- } \\
\text { gree } \\
(\%)\end{array}$ & \begin{tabular}{|c|}
3 \\
Neither \\
agree nor \\
disagree \\
$(\%)$ \\
\end{tabular} & $\begin{array}{c}4 \\
\text { Agree } \\
(\%)\end{array}$ & $\begin{array}{c}5 \\
\text { Strongly } \\
\text { Agree } \\
(\%)\end{array}$ & $\begin{array}{l}\text { Mean } \\
\text { Value }\end{array}$ & $\begin{array}{l}\text { Stand- } \\
\text { ard } \\
\text { Devia- } \\
\text { tion }\end{array}$ \\
\hline Q1 & $\begin{array}{l}\text { The experimental activity I per- } \\
\text { formed from distance was inter- } \\
\text { esting. }\end{array}$ & 6.00 & 6.00 & 26.00 & 39.00 & 23.00 & 3.68 & 1.07 \\
\hline Q2 & $\begin{array}{l}\text { Performing real experiments from } \\
\text { distance could enhance Physics } \\
\text { lessons. }\end{array}$ & 0.00 & 6.00 & 13.00 & 35.00 & 46.00 & 4.2 & 0.89 \\
\hline Q3 & $\begin{array}{l}\text { The distant activity I carried out } \\
\text { helped me understand the lesson. }\end{array}$ & 5.00 & 7.00 & 19.00 & 45.00 & 24.00 & 3.76 & 1.06 \\
\hline Q4 & $\begin{array}{l}\text { The remote experiment I conduct- } \\
\text { ed was easy to use. }\end{array}$ & 7.00 & 10.00 & 19.00 & 20.00 & 44.00 & 3.84 & 1.28 \\
\hline Q5 & $\begin{array}{l}\text { I would recommend this site to a } \\
\text { friend of mine who is involved in } \\
\text { Physics. }\end{array}$ & 8.00 & 5.00 & 13.00 & 41.00 & 33.00 & 3.85 & 1.18 \\
\hline & & \multicolumn{4}{|c|}{ No } & \multicolumn{3}{|c|}{ Yes } \\
\hline Q6 & $\begin{array}{l}\text { I conducted another remote } \\
\text { experiment on my own initiative. }\end{array}$ & \multicolumn{4}{|c|}{58.70} & \multicolumn{3}{|c|}{41.30} \\
\hline
\end{tabular}




\subsection{Other results}

Using Google Analytics access is provided to various statistical data concerning all pages that are hosted on our Website. Excluding all other pages, we concentrate on 2 pages (Greek and English Version) that they host the present remote experiments. We assume that users who connected to those two pages performed a remote experimental activity. This assumption is not far from truth, if we take into account the average time that users were connected to the experimentation pages. Consequently, analyzing results from all users who have performed remote experiments, for the past 36 months $(01 / 01 / 2015$ - 01/01/2018) using Google Analytics, several other findings did arise, such as

- Users' distribution per day of week

- Users' preferred device (PC, tablet, smart phone) to perform the distant activity

The day that users, from all over the world, chosen to connect and perform a remote experiment, is Monday while Friday is the day with the fewer visitors. All other days share almost the same number of hits. Furthermore, almost $26 \%$ of users connect during weekends. All relevant data are summarized in Table 4. At this point it must be stressed that data in table 4, regard visitors on both the Greek and English Version.

Another finding is that most users who conducted remote experiment used their desktop computers in comparison to tablets or Smart Phones. Results are presented in Table 5.

Further analysis, of data from Google Analytics, does show that there is an increase to Smart Phones usage from period 2015-2016 to period 2017-2018 (Table 6).

At this point we must stress that findings that appear in tables 4 and 5 include not only students of Group A and B but also users who did perform a distant activity from all over the world at their own initiative.

Table 4. User's distribution per day

\begin{tabular}{|l|c|c|c|c|c|c|c|}
\hline & \multicolumn{7}{|c|}{ Day of Week } \\
\cline { 2 - 8 } & Monday & Tuesday & Wednesday & Thursday & Friday & Saturday & Sunday \\
\hline Number of Users & 934 & 448 & 545 & 413 & 240 & 402 & 501 \\
\hline
\end{tabular}

Table 5. Device used to conduct remote experiments

\begin{tabular}{|l|c|c|c|}
\hline \multirow{2}{*}{} & \multicolumn{3}{|c|}{ Device } \\
\cline { 2 - 4 } & Smart Phone & Tablet & Personal Computer \\
\hline Percentage & $3.76 \%$ & $2.44 \%$ & $93.80 \%$ \\
\hline
\end{tabular}

Table 6. Mobile Usage Trends

\begin{tabular}{|l|c|c|c|}
\hline \multirow{2}{*}{} & \multicolumn{3}{|c|}{ Mobile Device } \\
\cline { 2 - 4 } & $\mathbf{2 0 1 5 - 2 0 1 6}$ & $\mathbf{2 0 1 6 - 2 0 1 7}$ & $\mathbf{2 0 1 7 - 2 0 1 8}$ \\
\hline Percentage & $2.52 \%$ & $2.54 \%$ & $10.29 \%$ \\
\hline
\end{tabular}




\section{Discussion}

Comparing responses of Group A to those of Group B several findings can be extracted. Data from table 6 show that Group B has more positive views about remote experiments compared to those of Group A.

In general, responses for Q1, Q3 and Q5 appear to have more or less the same pattern which is summarized in that Group B shows higher values to the Strongly Agree / Agree than Group A and lower values both for Strongly Disagree / Disagree and Neither agree / nor disagree than those of Group A. More specifically responses on the first question show that Group B has more positive views about how interesting was their remote activity, while Group A responded more negatively (15.2\%) (figure 2).

The same trend emerges as it concerns the question about whether the remote experiment helped them to understand the lesson. Again Group B shows more positive views on the Agree / Strongly Agree answers ( $\approx 70 \%)$, while Group A shows more negative views on the Disagree / Strongly Disagree answers (20\%).

Responses at question 5 (Q5) reveal the same pattern as Q1 and Q3. Almost 1 out of $4(24.8 \%)$ students of Group A Disagrees / Strongly Disagrees on the statement that he/she would propose the site to a friend of his/her, while the corresponding percentage of Group B is about 13.2\%. Group A and B share a difference of almost 20\% on the Agree / Strongly Agree responses on the same topic (figure 4).

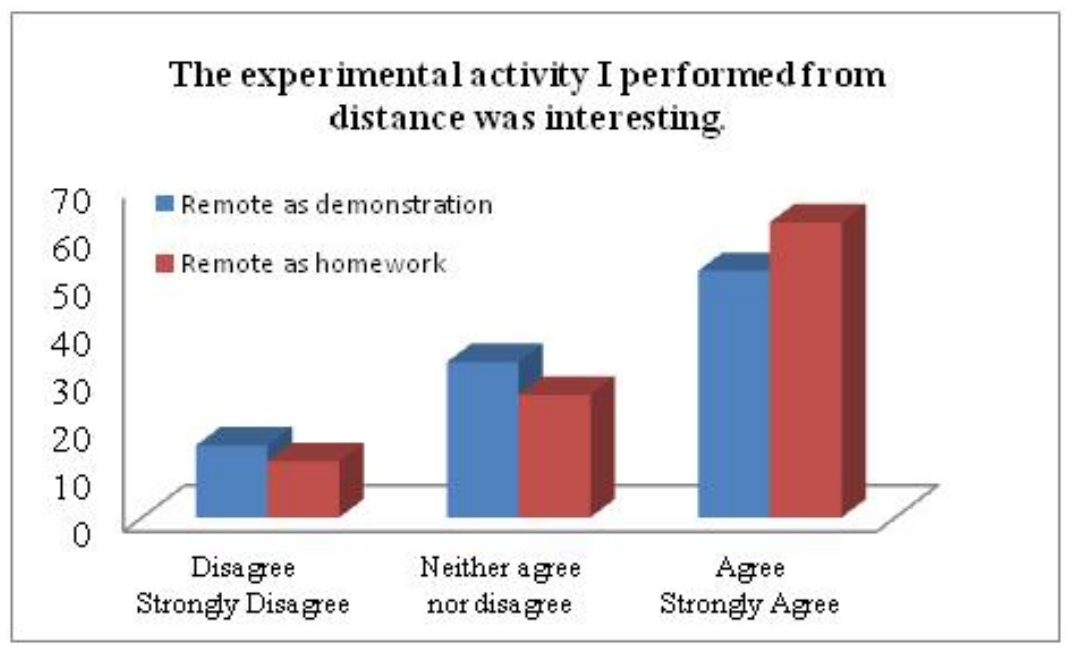

Fig. 2. Comparative results for Group A and B on Q1. 


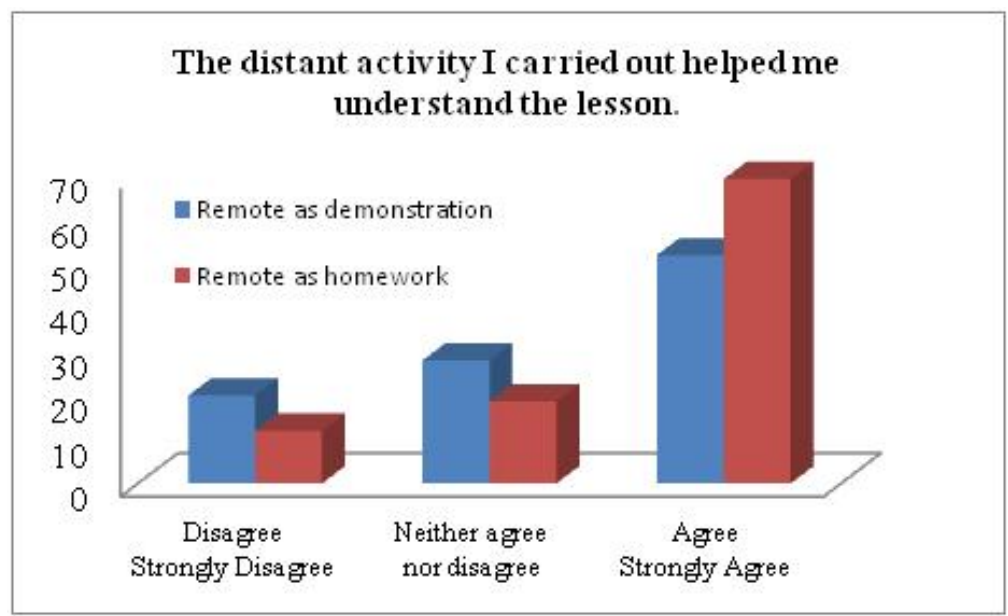

Fig. 3. Comparative results for Group A and B on Q3.

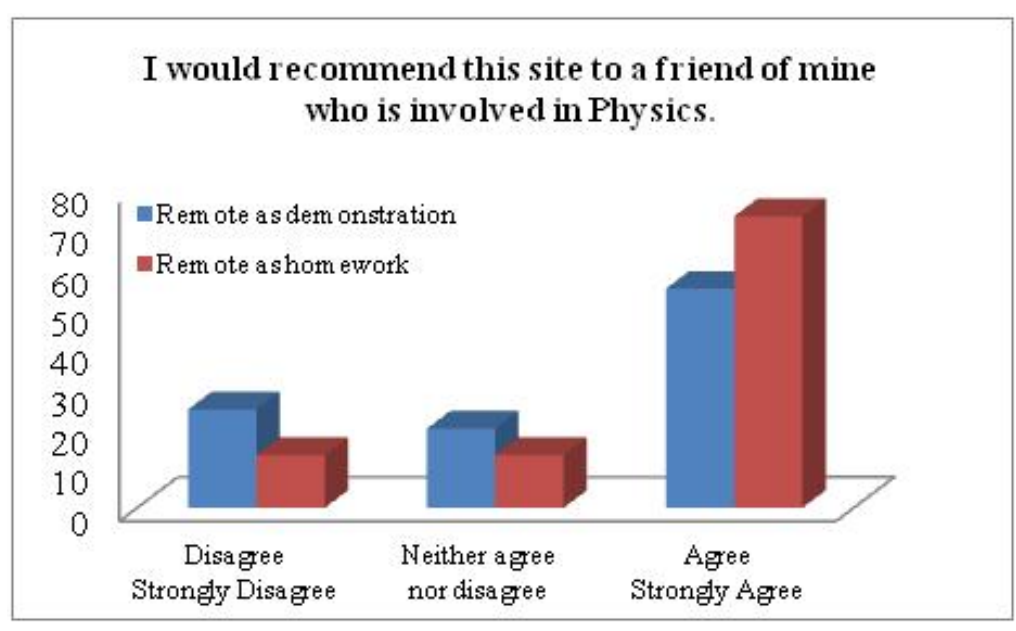

Fig. 4. Comparative results for Group A and B on Q5.

At figure 5, the comparative results of Group A and B as it concerns students' views on how easy it was to perform the experiment. As derives from figure 5, 41.1\% of Group A students do not have a clear cut view on the easy of use. This finding can be explained if we take under consideration that those students have not conducted the activity by themselves since they participated in a demonstration experiment. The percentage of Group B students drops at $18.67 \%$ for those that neither agree nor disagree. Furthermore, a percentage of $64 \%$ Agrees / Strongly Agrees that the distant activity was easy to perform (Group B) which is about $20 \%$ greater than those of Group A. Finally, 17.3\% of Group B Disagrees / Strongly Disagrees on the statement that the remote activity was easy to use, which is $4.4 \%$ greater than that of Group A. 
The great majority of students from Group A and Group B with percentages that come up to $88.6 \%$ and $81 \%$ respectively do Agree / Strongly Agree with the statement that remote experiments could enhance Physics lessons (figure 6).

A small number of students do not agree with the previous statement and reaches a percentage of 5.7\% and 6.3\% for Group A and Group B respectively. In the last question (which provide as possible answers Yes or No) students were asked if they conducted another remote experiment on their own initiative.

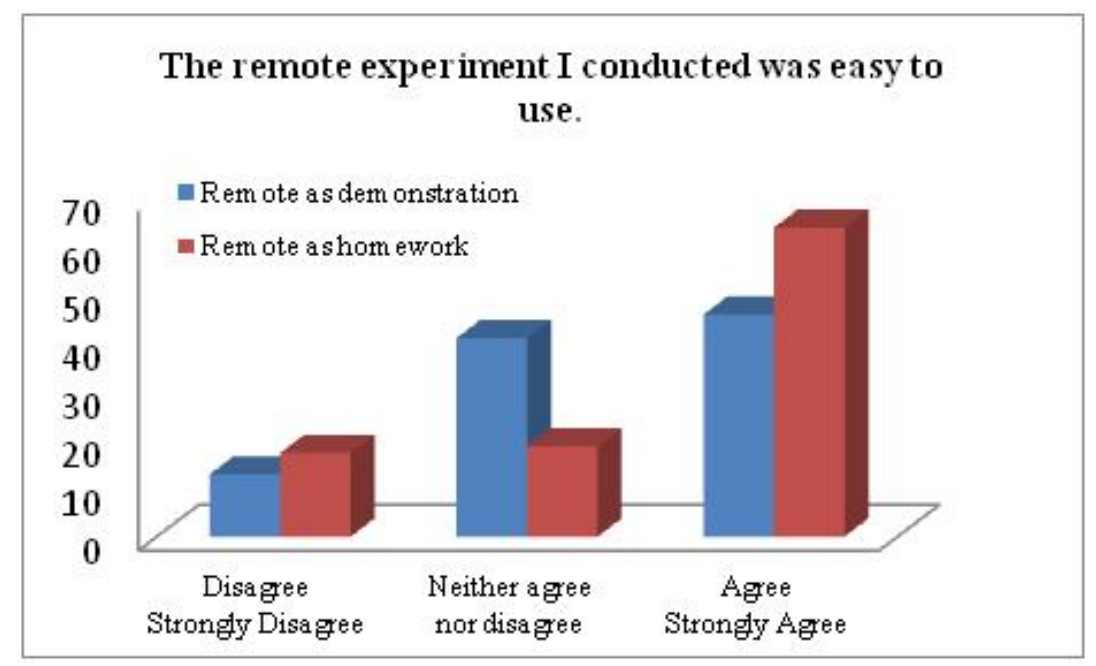

Fig. 5. Comparative results for Group A and B on Q4.

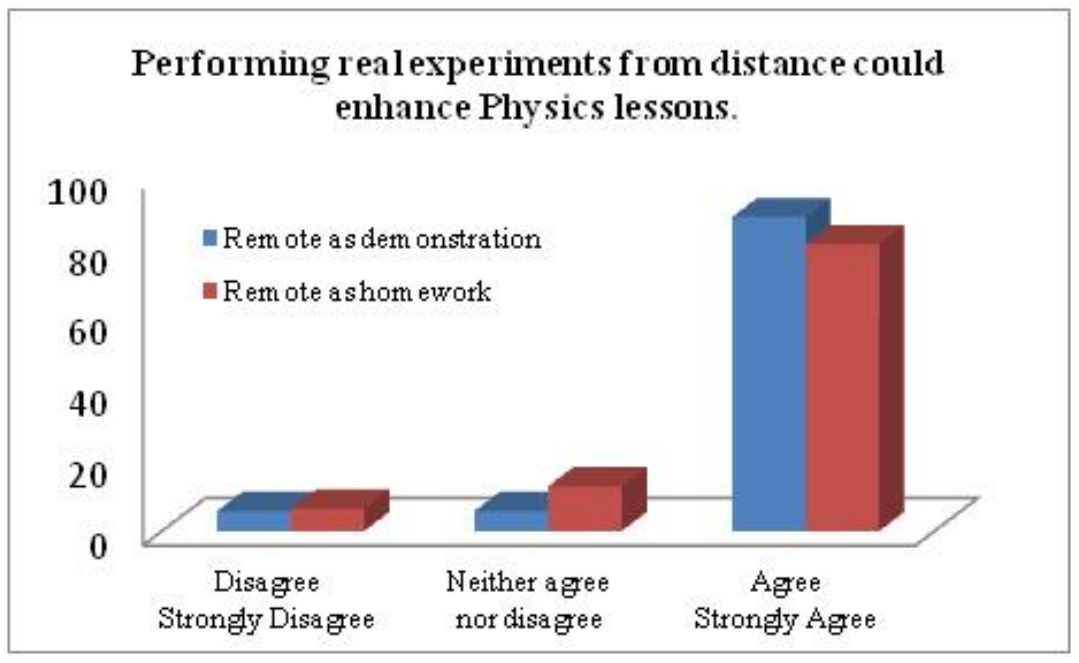

Fig. 6. Comparative results for Group A and B on Q2. 


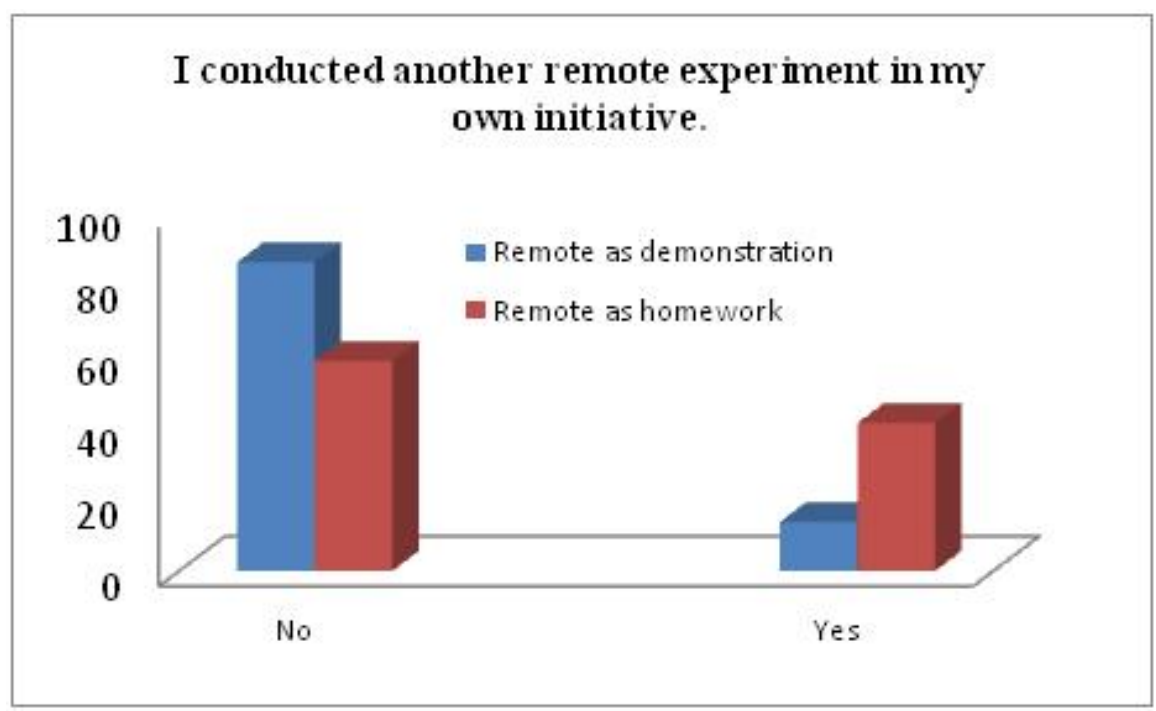

Fig. 7. Comparative results for Group A and B on Q6.

Responses are summarized and presented at figure 7. As it becomes obvious, a great majority of Group A students $(86.3 \%)$ did not perform another remote experiment on their own initiative, and only a small percentage of $13.7 \%$ did. This finding is in contrast with what Group B students report. A $41.3 \%$ percentage of students who performed the remote experiment as homework conducted another experiment on their own initiative, while a $58.7 \%$ did not. The difference between the two Groups reaches $27.6 \%$.

In general, we believe that all pre-mentioned differences are due to the different way remote experiments were used (demonstration / homework). Students that engaged in conducting remote experiments as homework seem better adopted the idea of controlling remotely an experimental apparatus and appear to have more positive views towards this mode of experimentation. In Table 7 we present a comparison of the mean values concerning both Groups at questions that were examined at our research.

Another outcome of the present study is that an increasing number of users (although still small) preferred to conduct remote experiments through their smart phones, indicating that the designers of such experiments should consider designing and developing responsive websites (desktop, tablet, mobile friendly websites).

Furthermore, one of the undeniable advantages of remote experiments is that are available 24/7. This advantage is being exploited and is confirmed by the current study since 1 out 4 users connected and performed a remote experiment during hours that school laboratories (and universities) are not available. 
Table 7. Comparison of Group A and Group B responses

\begin{tabular}{|c|c|c|c|c|}
\hline no. & \multicolumn{2}{|c|}{ Group A } & \multicolumn{2}{c|}{ Group B } \\
\hline & Mean Value & SD & Mean Value & SD \\
\hline Q1 & 3.63 & 1.16 & 3.68 & 1.07 \\
\hline Q2 & 4.54 & 0.89 & 4.2 & 0.89 \\
\hline Q3 & 3.44 & 1.29 & 3.76 & 1.06 \\
\hline Q4 & 3.51 & 1.18 & 3.84 & 1.28 \\
\hline Q5 & 3.45 & 1.32 & 3.85 & 1.18 \\
\hline Q6 & 1.55 & & 2.66 & \\
\hline
\end{tabular}

Finally, analyzing students' opinions on the conducted remote experiments we report the following positive statements:

S1: "...truth is that Physics is not my favorite subject. This experiment though seemed to me very interesting."

S2: “...what did impress me was that resistance was about 1 whatever voltage values I applied."

S3: "Congratulations for this work. The experiment was fantastic. Well done to the constructors. It is a very good solution for Physics lesson (if of course the strict school allows the usage of electronic means)."

On the contrary, other opinions stress the problems students faced during the conduction of remote experiments. Some of those are as follows.

S4: "For quite a time I could not access the site because somebody else was performing the experiment."

S5: “...it takes too long to access the site. I and my friends needed about a week. Please fix this problem."

As it is obvious students' opinions on remote experiments are positive in general, while there are some technical aspects which need to be improved, such as scheduling.

\section{Conclusion}

Summarizing the answers of Group A (students who performed the experiment as a demonstration) and Group B (students who performed the distant activity from their place) we are confident that there are qualitative and quantitative differences between the two groups. Since the only variable is the way that the remote experiment was conducted, we strongly believe that all differences are due to this fact.

Furthermore, as it has been revealed, users show the same preference among days to conduct a remote experiment except Friday which is the day with the lowest visitor rate. On the other hand, Desktop Computers seem to be the most preferable device for users to connect and perform a distant activity although Smart Phones seem to gain ground. This is a fact that remote experiments constructors have to take into account in order to build responsive pages.

In addition, from students' comments derives that a scheduling system is something that could prevent users' frustration and could provoke more positive views 
towards remote experiments. On the other hand, it is revealed from the comments that students did embrace the whole idea of remote experimentation.

Concluding, experimentation is a vital component of science and engineering education at all levels. Nowadays, due to several reasons, remote experiments seem to be gaining ground relatively to other available means to perform experiments. The present research focuses on the way remote experimentation should be implemented to achieve positive attitudes and thus improving the educational outcome. Our findings indicate that students' acceptance is greater when they perform a distant experiment in comparison to when they participate in a remote experiment as demonstration. Consequently, we are confident that remote experiments are more effective as students are involved actively in them.

\section{$6 \quad$ References}

[1] Bencomo, S. D. (2004). Control learning: Present and future. Annual Reviews in Control, 28(1), 115-136. https://doi.org/10.1016/j.arcontrol.2003.12.002

[2] Heradio, R., de la Torre, L., \& Dormido, S. (2016). Virtual and remote labs in control education: A survey. Annual Reviews in Control. https://doi.org/10.1016/j.arcontrol. 2016.08.001

[3] Alkhaldi, T., Pranata, I., \& Athauda, R. I. (2016). A review of contemporary virtual and remote laboratory implementations: observations and findings. Journal of Computers in Education, 3(3), 329-351. https://doi.org/10.1007/s40692-016-0068-Z

[4] Hanson, B., Culmer, P., Gallagher, J., Page, K., Read, E., Weightman, A., \& Levesley, M. (2009). ReLOAD: Real laboratories operated at a distance. IEEE Transactions on Learning Technologies, 2(4), 331-341. https://doi.org/10.1109/TLT.2009.35

[5] Látal, F. (2011). Remote teaching laboratories in Physics lessons-Attitudes of students and teachers to the remotely controlled experiments. Problems of Education in the 21st Centu$r y, 37$.

[6] Sicker, D. C., Lookabaugh, T., Santos, J., \& Barnes, F. (2005, October). Assessing the effectiveness of remote networking laboratories. In Frontiers in Education, 2005. FIE'05. Proceedings 35th Annual Conference (pp. S3F-S3F). IEEE.

[7] Lowe, D., Newcombe, P., \& Stumpers, B. (2013). Evaluation of the use of remote laboratories for secondary school science education. Research in Science Education, 43(3), 1197-1219. https://doi.org/10.1007/s11165-012-9304-3

[8] Garcia-Zubia, J., Hernandez, U., Angulo, I., Orduña, P., \& Irurzun, J. (2009). Acceptance, Usability and Usefulness of WebLab-Deusto from the Students Point of View. International Journal of Online Engineering, 5(1). https://doi.org/10.3991/ijoe.v5i1.817

[9] Corter, J. E., Esche, S. K., Chassapis, C., Ma, J., \& Nickerson, J. V. (2011). Process and learning outcomes from remotely-operated, simulated, and hands-on student laboratories. Computers \& Education, 57(3), 2054-2067. https://doi.org/10.1016/j.compedu.2011.04.0 09

[10] Lobo, M. C., Alves, G. R., Marques, M. A., Viegas, C., Barral, R. G., Couto, R. J., ... \& Alves, J. (2011, October). Using remote experimentation in a large undergraduate course: Initial findings. In Frontiers in Education Conference (FIE), 2011 (pp. S4G-1). IEEE.

[11] Lerro, F., \& Marchisio, S. (2015, September). Preferences and uses of a remote lab from the students' viewpoint. In Interactive Collaborative Learning (ICL), 2015 International Conference on (pp. 854-857). IEEE. 
[12] Nickerson, J. V., Corter, J. E., Esche, S. K., \& Chassapis, C. (2007). A model for evaluating the effectiveness of remote engineering laboratories and simulations in education. Computers \& Education, 49(3), 708-725. https://doi.org/10.1016/j.compedu.2005.11.019

[13] Hsu, S. H. (2008). Developing an index for online customer satisfaction: Adaptation of American Customer Satisfaction Index. Expert systems with Applications, 34(4), 30333042. https://doi.org/10.1016/j.eswa.2007.06.036

[14] Johnson, M. D., Gustafsson, A., Andreassen, T. W., Lervik, L., \& Cha, J. (2001). The evolution and future of national customer satisfaction index models. Journal of economic Psychology, 22(2), 217-245. https://doi.org/10.1016/S0167-4870(01)00030-7

[15] Finn, A., Wang, L., \& Frank, T. (2009). Attribute perceptions, customer satisfaction and intention to recommend e-services. Journal of Interactive Marketing, 23(3), 209-220. https://doi.org/10.1016/j.intmar.2009.04.006

[16] Cho, N., \& Park, S. (2001). Development of electronic commerce user-consumer satisfaction index (ECUSI) for Internet shopping. Industrial Management \& Data Systems, 101(8), 400-406. https://doi.org/10.1108/EUM0000000006170

[17] Lowe, D. (2013). Integrating reservations and queuing in remote laboratory scheduling. IEEE Transactions on Learning Technologies, 6(1), 73-84. https://doi.org/10.1109/ TLT.2013.5

\section{$7 \quad$ Authors}

Nikos Dintsios is with Aristotle University of Thessaloniki, Department of Physics, 54124 Thessaloniki, Greece.

Stamatia Artemi is with Aristotle University of Thessaloniki, Department of Physics, 54124 Thessaloniki, Greece.

Hariton Polatoglou is with Laboratory of Didactics of Physics and Educational Technology, 54124 Thessaloniki, Greece.

Article submitted 11 April 2018. Resubmitted 22 April 2018. Final acceptance 05 May 2018. Final version published as submitted by the authors. 